\title{
Chirped Fiber Bragg Gratings for WDM Chromatic Dispersion Compensation in Multispan 10-Gb/s Transmission
}

Isabelle Riant, Salim Gurib, Josselyne Gourhant, Pierre Sansonetti, Christian Bungarzeanu, and Raman Kashyap

(Invited Paper)

\begin{abstract}
We report here the fabrication of fiber chromatic dispersion compensators, along with the tests of those components in wavelength-division-multiplexed transmission at $10 \mathrm{~Gb} / \mathrm{s}$ and an analysis of their performance by simulation.
\end{abstract}

Index Terms-Bragg reflectors, dispersion compensation, fiberoptics components, optical communications, systems.

\section{INTRODUCTION}

A MONG the different possible methods for achieving chromatic dispersion compensation-the major limitation for today's high speed telecommunication networks-the chirped fiber Bragg grating (FBG), [dispersion compensating grating (DCG)] is a very promising candidate because of its high figure of merit (FOM) [1], and its capacity for working in wavelength-division-multiplexed (WDM) operation [2]-[4]. Here, we report two methods to realize chromatic dispersion compensators, results on fabrication and tests of components in four wavelengths multispan WDM systems at $10 \mathrm{~Gb} / \mathrm{s}$. We then analyze the system performance by simulation and compare the results with experimental behavior. This work was carried out in the frame of two ACTS programs: PHOTOS and OPEN. Gratings were fabricated at British Telecom Laboratories and at Alcatel, tested at Alcatel, and simulation carried out at the Ecole Polytechnique of Lausanne.

\section{GRATING FABRICATION}

Five sets of dispersion compensating gratings (DCG's) were realized at four ITU channels: 1549.32, 1552.52, 1555.75, and $1558.98 \mathrm{~nm}$. The two central wavelengths were fabricated at BT Laboratories while the others at Alcatel. The DCG's were designed to compensate a fiber dispersion around $1200 \mathrm{ps} / \mathrm{nm}$ corresponding to about $80 \mathrm{~km}$ of standard telecom fiber.

Manuscript received March 23, 1999. This work was supported by two ACTS programs: PHOTOS and OPEN with the participation of Alcatel Corporate Research Center, Ecole Polytechnique de Lausanne, and British Telecom Laboratories.

I. Riant, S.Gurib, J. Gourhant, and P. Sansonetti are with Alcatel Corporate Research Center, 91460 Marcoussis, France.

C. Bungarzeanu is with the Swiss Federal Institute of Technology Lausanne (EPFL), Telecommunications Laboratory, CH-1015 Lausanne, Switzerland.

R. Kashyap is with BT Laboratories, Ipswich IP5 3RE, U.K.

Publisher Item Identifier S 1077-260X(99)07936-8.
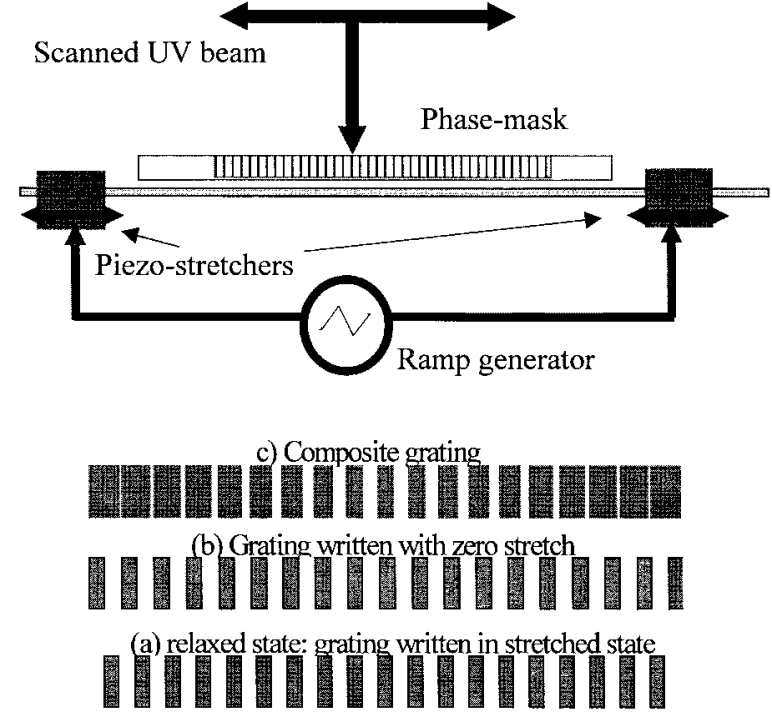

Fig. 1. Schematic of the symmetric stretch scheme for writing apodized gratings. (a), (b) Two gratings combined to generate (c) the composite grating. The experimental arrangement is shown immediately above the composite grating.

\section{A. Grating Fabrication by Symmetric Stretch}

Five near identical gratings per channel were fabricated, one set at $1552 \mathrm{~nm}$ and the other at $1555.75 \mathrm{~nm}$, at BT Laboratories. 100-mm-long step-chirped phase masks [5], nominally on the ITU grid of wavelengths, also manufactured at BT Laboratories, were used for the fabrication of the gratings. The fabrication scheme has been published elsewhere [6]. Briefly, the UV source used for fabrication is a frequency doubled argon laser operating at $244 \mathrm{~nm}$ [7], with $200 \mathrm{~mW}$ of CW power. Deuterated boron-germanium codoped fiber [8] is placed in near contact with the phase-mask and the UV beam scanned across it [9]. Cosine envelope apodization is achieved during the writing of the fiber grating by repetitively stretching the fiber symmetrically around the centre of the grating [10]. This method ensures that each grating is identically apodized with great simplicity, and has produced very-high-quality gratings [10]. A schematic of the scheme is shown in Fig. 1. The repetitive stretch effectively writes two overlapped gratings which are out of phase at the edges, but in phase in the middle. The reflectivity and the deviation 


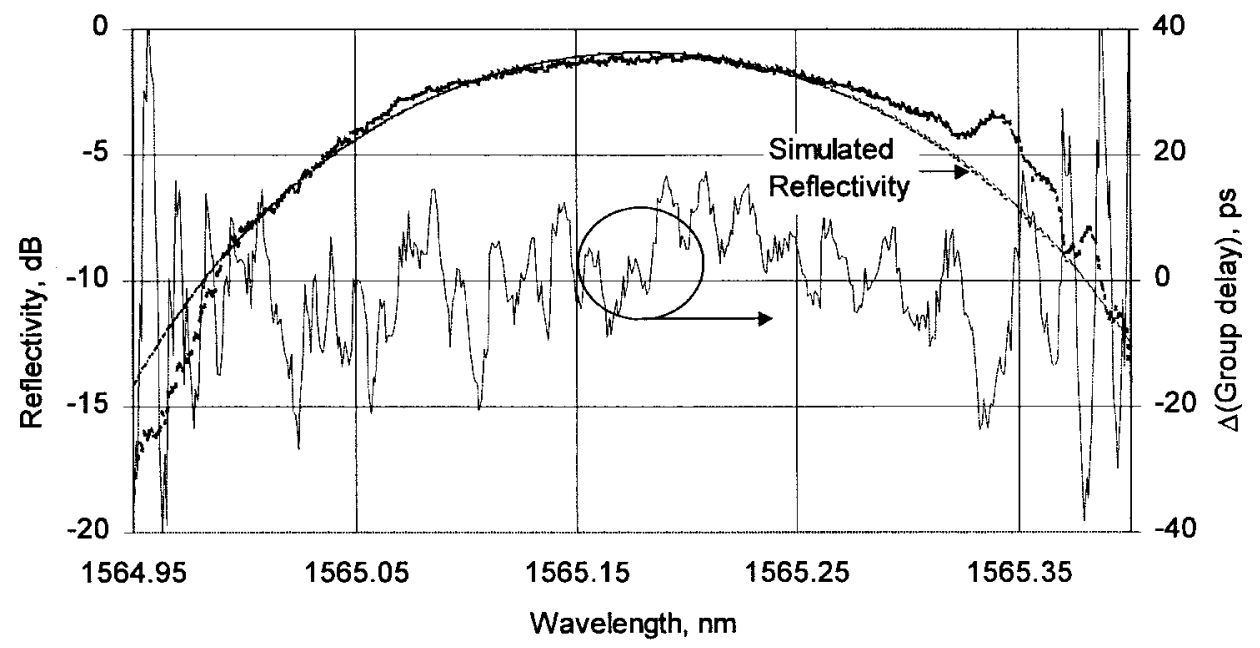

Fig. 2. Reflectivity and group delay difference (from a slope of $1450 \mathrm{ps} / \mathrm{nm}$ ) of a grating apodized by the symmetric stretch method. The simulated reflectivity with a raised cosine (exponent of 2) apodization profile is also shown. The ripple in the delay is primarily due to the phase-mask stitch error apparent in the reflectivity spectrum around a wavelength of $1565.35 \mathrm{~nm}$.

from a dispersion of $1450 \mathrm{ps} / \mathrm{nm}$ of a well apodized grating is shown in Fig. 2. The deviation from linear dispersion over a bandwidth of $\sim 0.4 \mathrm{~nm}$ is generally $< \pm 10 \mathrm{ps}$. The spectra are dependent on the quality of the phase mask, and it is apparent that there is a phase-stitch on the long wavelength end of the grating reflectivity spectrum shown in Fig. 2. Also possible with this fabrication method are channelized gratings which not only equalize the dispersion but also the group delay. These are fabricated by concatenating the gratings such that each 100 -mm-long apodized grating for the consecutive channel is written sequentially in the succeeding $100 \mathrm{~mm}$ length of fiber. The reflectivity and group delay spectra for a 400-mm-long grating which acts as a simultaneous dispersion compensator for 4 channels and a group delay equalizer for three channels is shown in Fig. 3. The fifth channel has been written out of sequence, in the position of the fourth grating; this is the reason why the delay for the longest wavelength channel begins at the point at which the third channel ends. The principle of concatenating gratings in this way has been demonstrated for 20 channels in a 2-m-long grating [11]. The reflectivity and the group delay of four gratings of one channel, used in the experiments reported in this paper are shown in Fig. 4(a)-(d). The reflectivity is close to $90 \%$, the spectral bandwidth is about $0.4 \mathrm{~nm}$, and chromatic dispersion around $1350 \mathrm{ps} / \mathrm{nm}$.

\section{B. Grating Fabrication by Telescopic Scanning}

Two sets of five gratings were fabricated at 1549.3 and at $1559 \mathrm{~nm}$ at Alcatel using the method of telecsopic scanning described in [12]. This method is simple, inexpensive and versatile, allows the inscription of gratings with arbitrary chirp and center wavelength using a single unchirped phase mask.

This technique is based on the process reported in [13] permitting the control of the grating wavelength with a phase mask of given pitch, by modifying the UV beam convergence. By writing a succession of small elementary gratings and, between each grating, changing the beam convergence, it is possible to write step-chirped gratings [5]. This method allows the choice of the central wavelength of the grating and to also

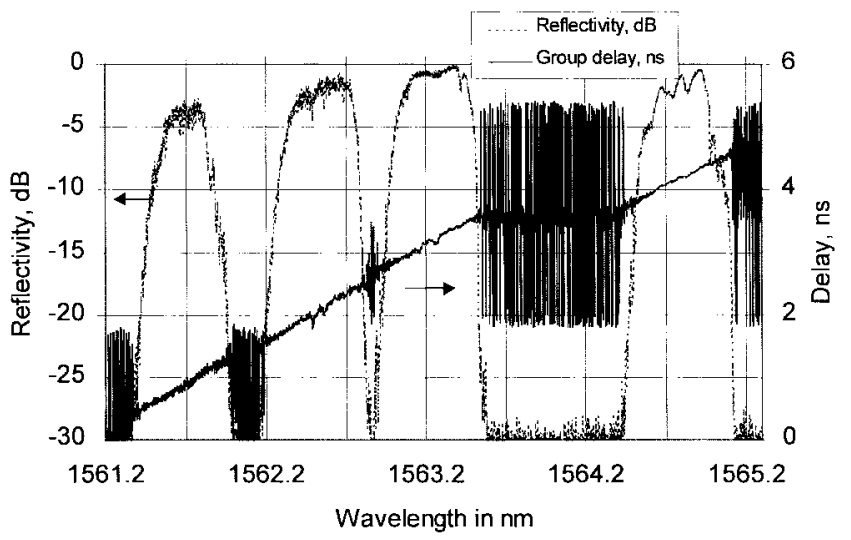

Fig. 3. Three-channel group-delay equalizer and four-channel dispersion compensator.

apodize the grating profile by controlling the irradiation time on each elementary grating at the same time. The technique of apodization creates a slight asymmetry in the reflection spectrum. This can be overcome with a second irradiation, which is fringeless and follows a profile inverse to that of the index modulation. This asymmetry has been neglected for the first realized gratings. A fabrication setup has two motorized translation stages. One is placed under the mount holding the phase mask and the fiber for elementary grating concatenation. For beam convergence tuning, the other one is simply placed under the second lens of the afocal arrangement used to expand the beam of an excimer laser. The computer controlled setup is presented in Figs. 5 and 6 shows the Bragg wavelength variation versus lens position with the fiber in contact with the phase mask. This variation may be further amplified by increasing the distance between the fiber and the mask [13] up to about $\pm 15 \mathrm{~nm}$.

Using this technique chirped apodized gratings have been realized in a highly germanium-doped fiber with a corecladding index difference of $3.3 \times 10^{-2}$. This fiber is highly photosensitive so that hydrogen loading can be avoided. The effective index of this fiber at wavelengths of interest is 1.46, 


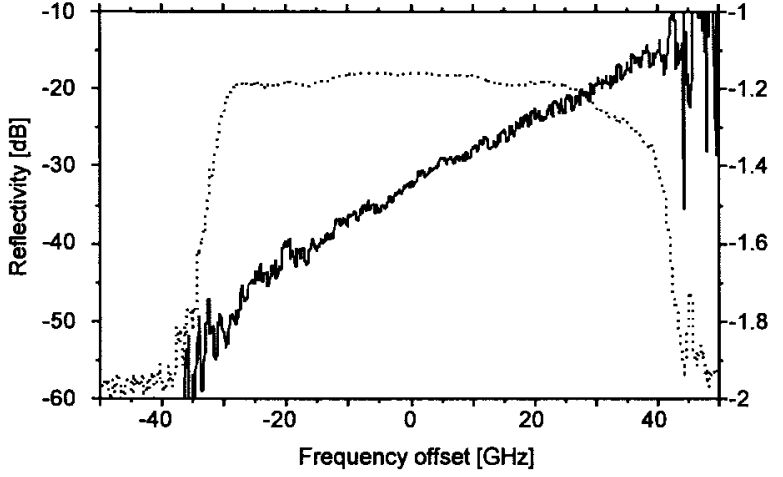

(a)

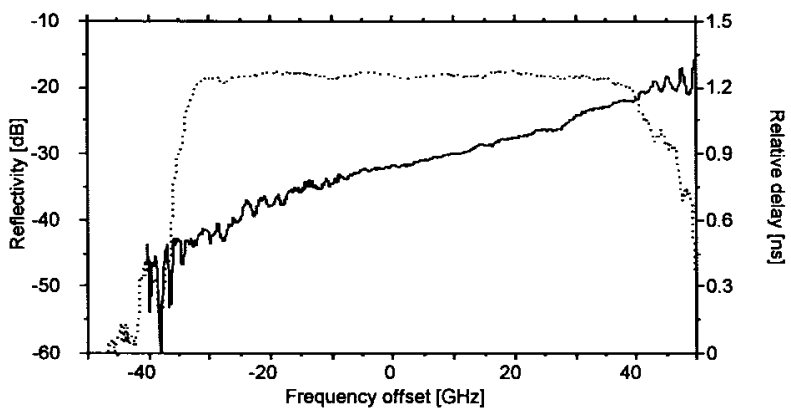

(c)

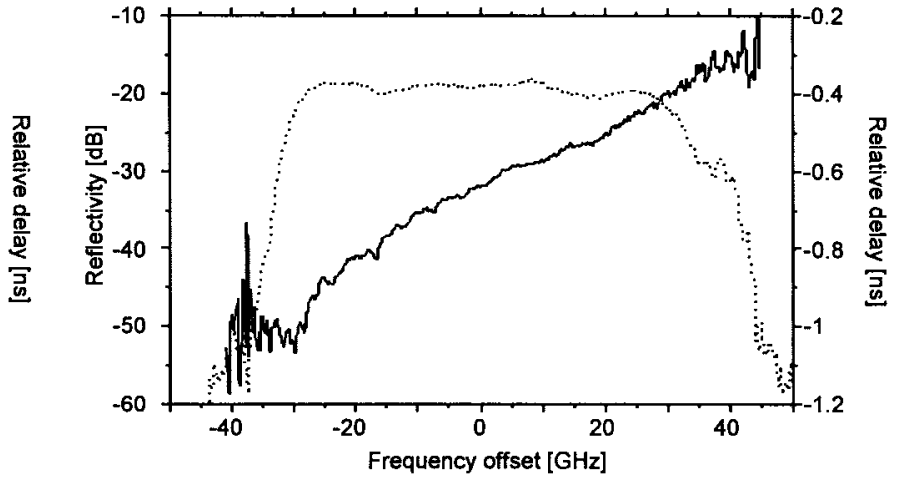

(b)

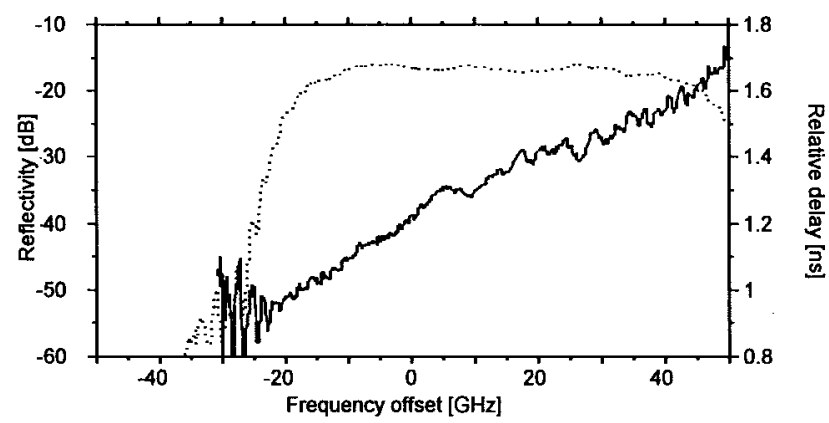

(d)

Fig. 4. (a)-(d) Reflectivity and group delay spectra of four 100-mm-long gratings fabricated at BT Laboratories.

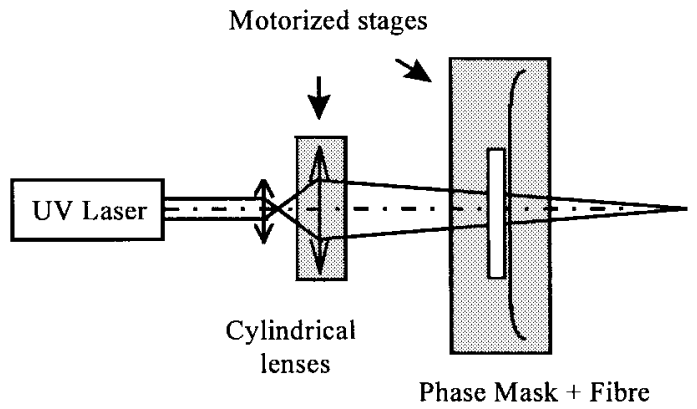

Fig. 5. Fabrication setup for chirped apodized gratings at different wavelengths.

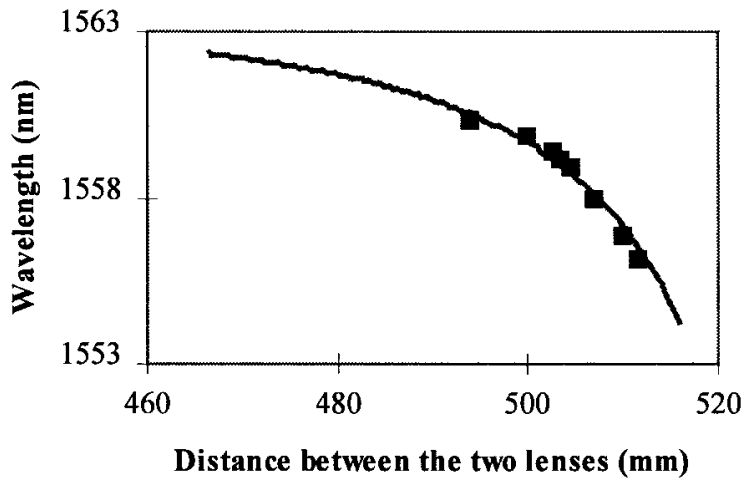

Fig. 6. Bragg wavelength variation as a function of the distance between the two lenses, the fiber being in contact with the phase mask. The focal lengths of the two lenses in the UV are 45.3 and $270.6 \mathrm{~mm}$. In a focal position, the distance between the two lenses is $315.9 \mathrm{~mm}$. The line represents simulation and the squares give experimental results.

and our phase mask has a period of $1071 \mathrm{~nm}$ resulting in uniform gratings with a Bragg wavelength of $1563.7 \mathrm{~nm}$. Using this fiber and phase mask, chirped gratings can be

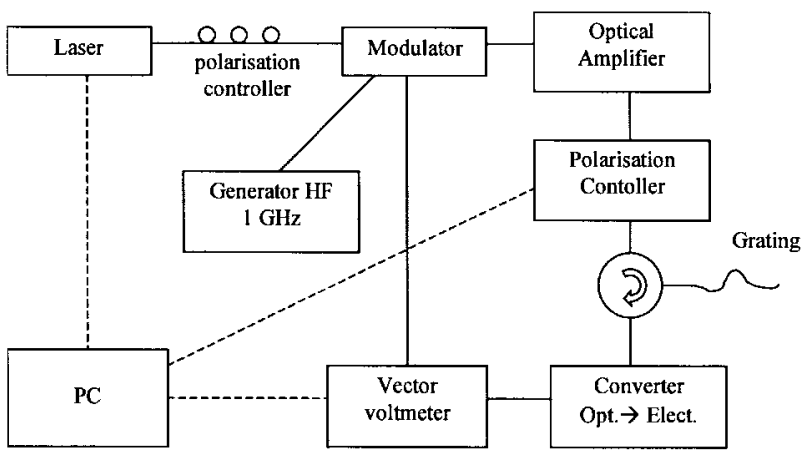

Fig. 7. Measurement setup for chromatic dispersion compensator characterization.

fabricated at $1559 \mathrm{~nm}$. They are $60 \mathrm{~mm}$ long and have a chirp of $0.46 \mathrm{~nm}$ with an apodized profile. The resulting spectral bandwidth is around $0.35-0.4 \mathrm{~nm}$. Group delays are measured using a tunable laser source, modulated at $1 \mathrm{GHz}$, and a vector voltmeter to detect phase shifts as a function of wavelength [14]. The measurement setup is described on Fig. 7. The group delay and reflectivity spectrum is shown in Fig. 8 for gratings numbered: 11142, 11145,11 148, 11 147, and 12003 at $1559 \mathrm{~nm}$ and in Fig. 9 for gratings numbered: 01 040, 01 046, 01 045, 01 048, and 01044 at $1549.3 \mathrm{~nm}$.

The reflectivity of each grating is around $75 \%$ and chromatic dispersion near $-1200 \mathrm{ps} / \mathrm{nm}$. The group delay deviation is below \pm 30 ps. This deviation for one of such grating, for which deviation is less than $\pm 20 \mathrm{ps}$, is shown in Fig. 10. The sharp hops observed on this curve are attributed to polarization mode dispersion (PMD) effects. Indeed, we have measured for those gratings, using a HP polarimeter, PMD between 11 and 


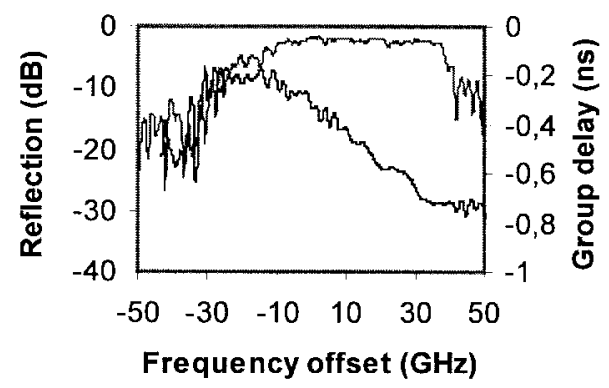

(a)

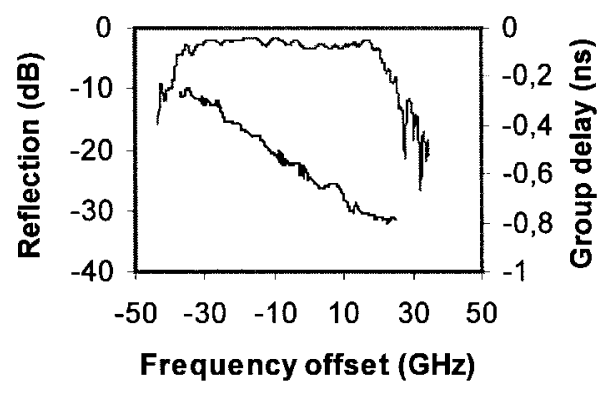

(c)

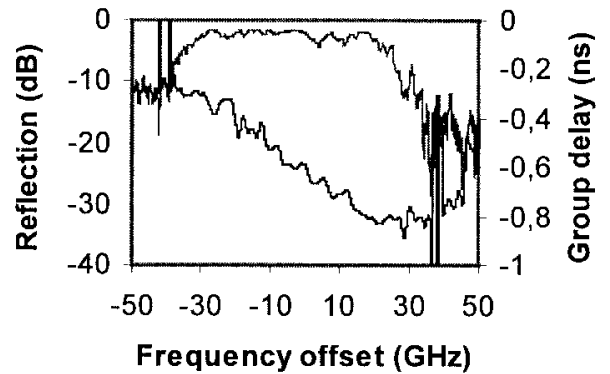

(b)

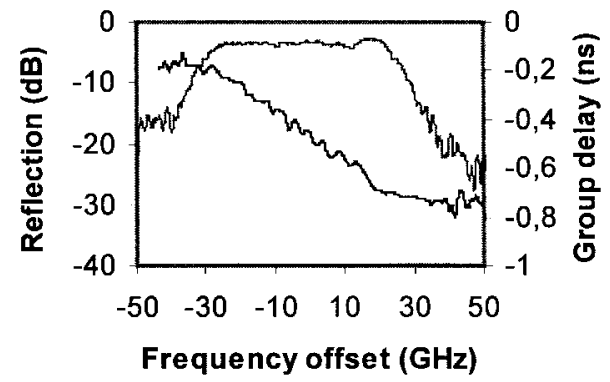

(d)

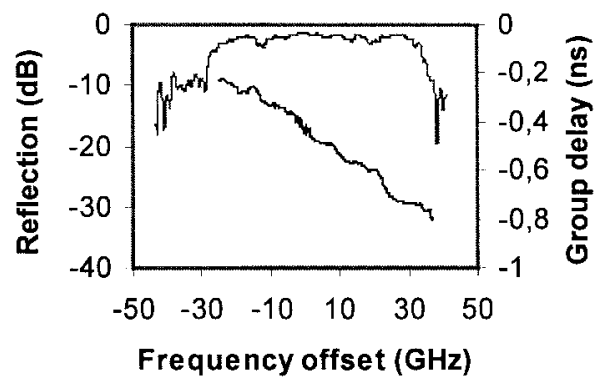

(e)

Fig. 8. Reflectivity and group delay spectra for chromatic dispersion compensators. (a) 11142 . (b) 11145 . (c) 11147 . (d) 11148 . (e) 12003 ) realized by Alcatel at $1559 \mathrm{~nm}$. There are represented versus frequency offset with frequency reference et $1559 \mathrm{~nm}$.

20 ps. Since then, analysis has shown that grating PMD is proportional to fiber birefringence and chromatic dispersion [15]-[17]. The fiber used in this experiment exhibits a strong birefringence in the order of $8.4 \times 10^{-6}$ leading for a DCG of $1200 \mathrm{ps} / \mathrm{nm}$ to a PMD of $\sim 11 \mathrm{ps}$.

During fabrication, the length and the irradiation time are adapted to the dimensions of the UV spot for each elementary grating as a function of beam convergence. However, concatenation has not yet been optimized, introducing phase shift errors at a nearly periodic spacing. The length of the elementary gratings is around $200 \mu \mathrm{m}$, introducing a sampled structure (presence of secondary filters) with a period close to $4 \mathrm{~nm}$. This is shown for one of the DCG in Fig. 11. The rejection is not yet adequate, and furthermore, the period of the superstructure reflection is very close to the channel spacing $(400 \mathrm{GHz})$ and can affect WDM operation. The unit length of the small gratings can be reduced to further reject the secondary filters in the spectrum. Although they are not optimized, these gratings have been used in WDM system transmission by careful choice of the order of channel wavelengths. Gratings from BTL, with an out-of-band rejection close to $40 \mathrm{~dB}$, are placed directly after the circulator, in order to nearly completely reflect the signals at 1552 and $1555 \mathrm{~nm}$. The Alcatel gratings are placed after these. The superstructure reflections near 1552 and $1555 \mathrm{~nm}$ do not affect, or have an insignificant effect on the first gratings since the signals at those wavelengths have already been reflected.

It should be pointed out that the fabrication of the chromatic dispersion compensators at $1549 \mathrm{~nm}$ is more complicated than at $1559 \mathrm{~nm}$ because the Bragg wavelength variation as a function of lens displacement is sharper. This introduces a problem to attain the precise central wavelength. Time limitations prevented further optimization to allow the fabrication of DCG's at identical wavelengths, making the cascading of these gratings a bit more difficult.

\section{SySteM TeStS}

The 20 DCG's (five sets at four ITU channels) have been evaluated in a WDM scheme at $10 \mathrm{~Gb} / \mathrm{s}$. Fig. 12 shows the implementation of the experimental setup used for systems characterization. The WDM transmitter consists of four tuneable external cavity lasers. These sources are combined by a four by one coupler to a $\mathrm{LiNbO}_{3}$ Mach-Zehnder modulator (MZM) driven by a $2^{23}-1$ pseudorandom bit sequence (PRBS) 


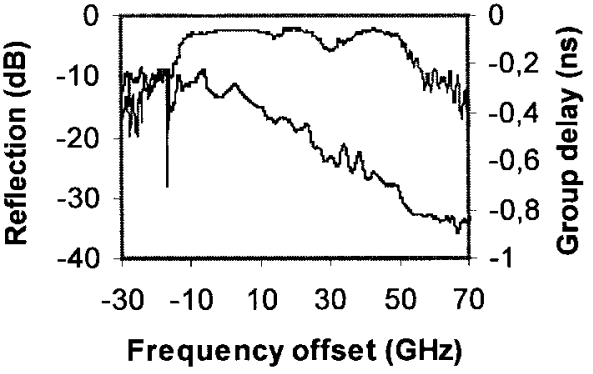

(a)

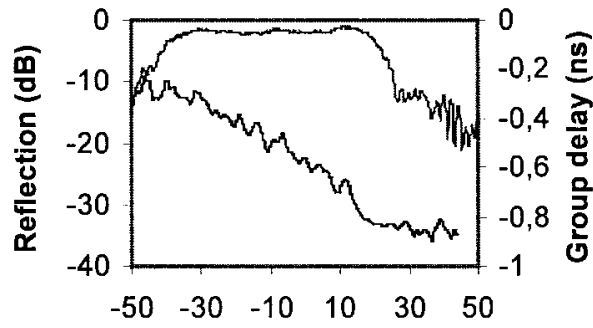

Frequency offset (GHz)

(c)

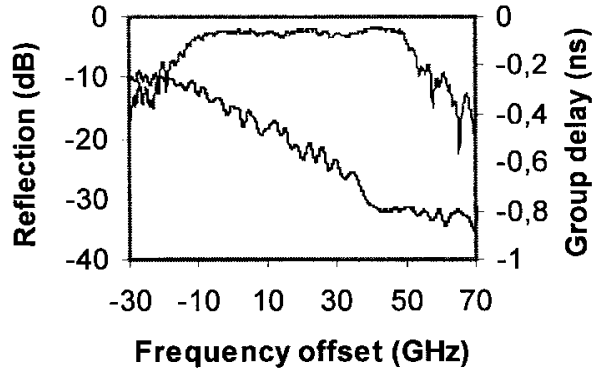

(b)

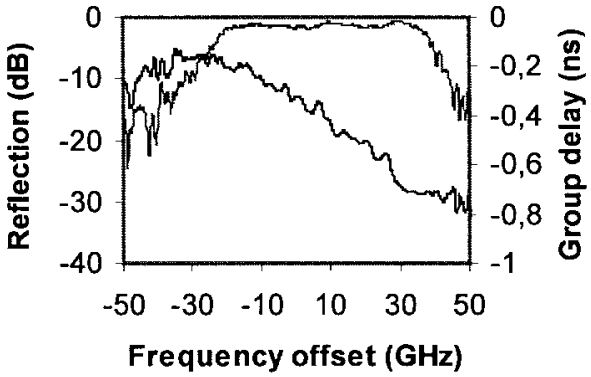

(d)

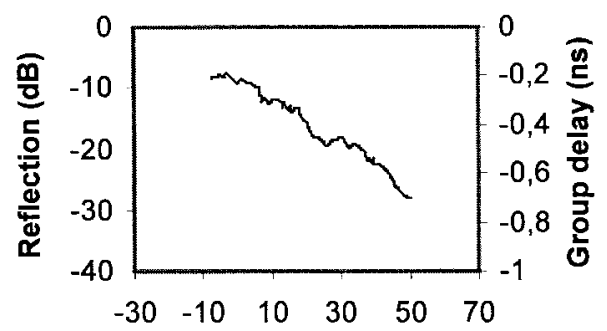

Frequency offset (GHz)

(e)

Fig. 9. Reflectivity and group delay spectra for chromatic dispersion compensators. (a) 01040 . (b) 01046. (c) 01045 . (d) 01048 ) and group delay spectrum for 01044 , realized by Alcatel at $1549 \mathrm{~nm}$. There are represented versus frequency offset with frequency reference et $1549.3 \mathrm{~nm}$.

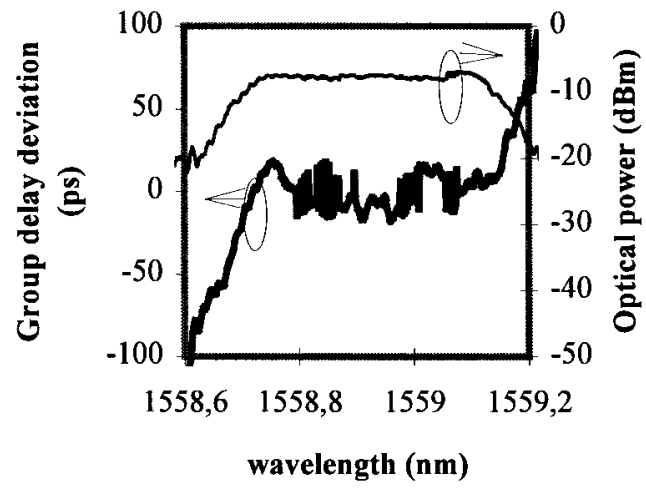

Fig. 10. Reflectivity spectrum and group delay deviation for a chromatic dispersion compensator realized by Alcatel (11 148). The group delay is here below $\pm 20 \mathrm{ps} / \mathrm{nm}$. For this measurement, the tuneable laser source is modulated at $2.5 \mathrm{GHz}$ and a network analyzer is used to detect phase shifts as a function of wavelength.

at $10 \mathrm{~Gb} / \mathrm{s}$. The pre- and the in-line power amplification is provided by dual-stage hybrid flat-gain erbium-doped fiber amplifiers (EDFA's). Low-noise figures (between 5.3 and 6.8 $\mathrm{dB}$ ) are obtained by $980-\mathrm{nm}$ pumping of the silica-based first stages (EDF). The second stages incorporate fluoride-based

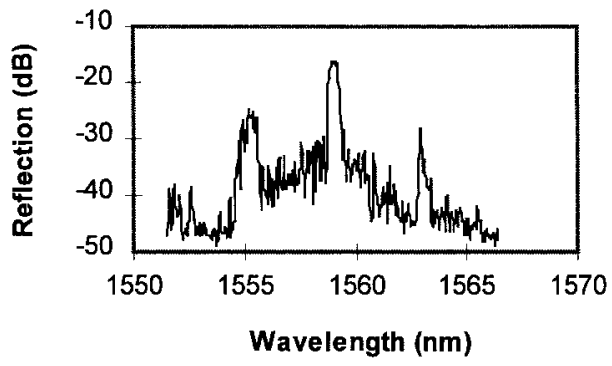

Fig. 11. Reflectivity spectrum for a chromatic dispersion compensator realized by Alcatel (11142). The reference level of the reflection is arbitrary.

erbium-doped fibers (EDFF), pumped at $1480 \mathrm{~nm}$ for flat gain and high output powers. Typical gains ranging from 28 to 31 $\mathrm{dB}$ with less than $2-\mathrm{dB}$ excursion over $25 \mathrm{~nm}$, and $20 \mathrm{dBm}$ output powers are obtained. The DCG's and an attenuator are coupled to optical circulators and placed between the stages of the pre- and the in-line amplifiers respectively. Optical attenuators are placed at the input of the transmission line composed of five spools of $80 \mathrm{~km}$ of nondispersion shifted (NDS) fibers with a mean chromatic dispersion of 17 $\mathrm{ps} / \mathrm{nm} / \mathrm{km}$. Typical values of $3 \mathrm{dBm}$ per channel are used to 


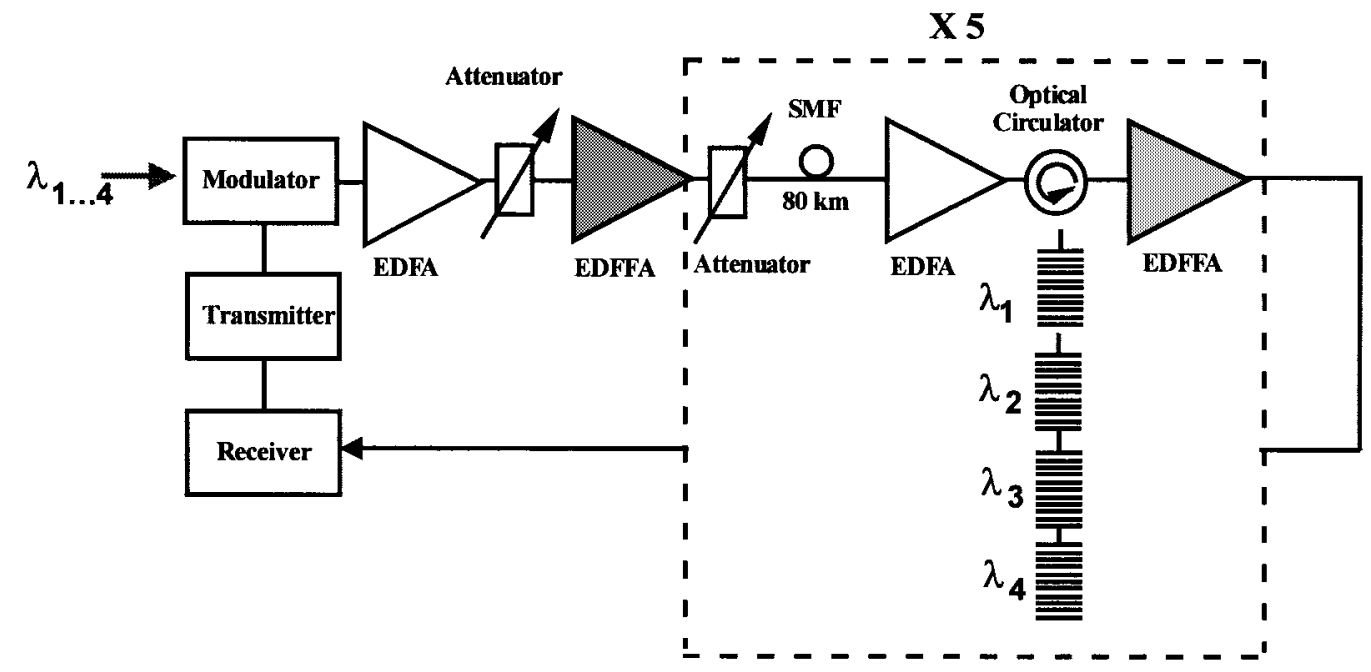

Fig. 12. Experimental setup for system characterization of CDC's.

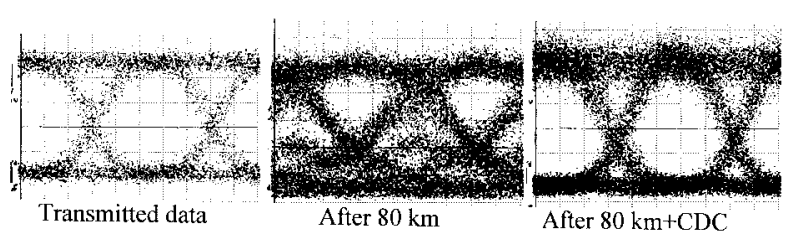

Fig. 13. Eye diagrams at the input, after $80 \mathrm{~km}$ without compensation and with compensation.

ensure operation in the linear regime. The receiver consists of a preamplifier, two 0.4- and 1.2-nm bandwidth filters, and a $10-\mathrm{Gb} / \mathrm{s}$ electrical receiver.

The system characterization starts by launching each wavelength individually through the whole transmission line $(5 \times 80$ $\mathrm{km}$ ) and by using the DCG's independently. The best BER measurements are recorded by fine tuning the input wavelength to overcome the problems due to variations in the time delay. The wavelength must be positioned with an accuracy of \pm 0.01 nm. Fig. 13 shows the eye diagrams for the transmitted data, at the output of $80 \mathrm{~km}$ of NDS fiber without and with a DCG centred at $1549 \mathrm{~nm}$, respectively.

Good reshaping of the signal is obtained with dispersion compensation. The transmission quality is analyzed by BER measurements and Fig. 14 shows the typical BER curves obtained in function of the received power and for different distances through the link. It can be seen that for this wavelength, BER floors at $10^{-10}$ appears at $320 \mathrm{~km}$. This was predictable since the DCG's were not exactly centred at the same wavelength.

Table I gives the penalty obtained for a BER at $10^{-10}$ for each wavelength.

For reasons previously described, these DCG's are then fused together in the following order: 1552, 1555, 1549, and $1559 \mathrm{~nm}$. The WDM operation is carried out by fine tuning the wavelengths as already mentioned. Fig. 15 shows the input and output spectra after $400 \mathrm{~km}$. It can be seen that the channels at 1549 and $1559 \mathrm{~nm}$, placed at the end of the chain, experience extra losses compared to the central ones. This results in poor

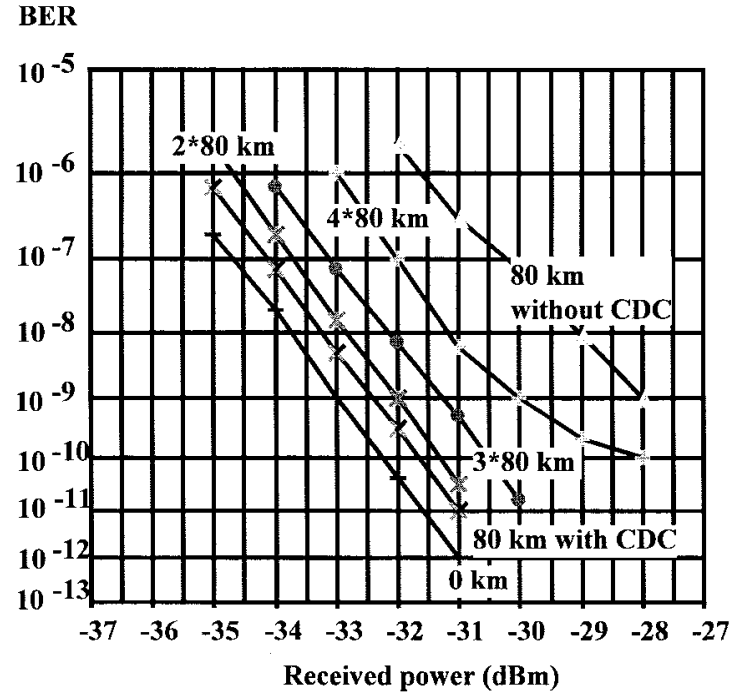

Fig. 14. BER curves for channel at $1549 \mathrm{~nm}$.

TABLE I

\begin{tabular}{c|c|c|c|c}
\hline Distance (km) & \multicolumn{4}{|c}{ Penalty, dB } \\
\hline $\mathbf{8 0}$ & 0.6 & 0.8 & 1.3 & 1.6 \\
\hline $\mathbf{2 \times 8 0}$ & 1 & 3.3 & 1.4 & 2.3 \\
\hline $\mathbf{3 \times 8 0}$ & 1.7 & 1.8 & 0.4 & 1.9 \\
\hline $\mathbf{4 \times 8 0}$ & floor at $10^{-10}$ & 4.2 & 0.4 & 2.9 \\
\hline $\mathbf{5 \times 8 0}$ & & 4.4 & 1.6 & floor at $10^{-10}$ \\
\hline Wavelength (nm) & $\mathbf{1 5 4 9}$ & $\mathbf{1 5 5 2}$ & $\mathbf{1 5 5 5}$ & $\mathbf{1 5 5 9}$ \\
\hline
\end{tabular}

TABLE II

\begin{tabular}{c|c|c}
\multicolumn{2}{c}{ Wavelength (nm) } \\
\hline Distance (km) & $\mathbf{1 5 5 2}$ & $\mathbf{1 5 5 5}$ \\
\hline $\mathbf{8 0}$ & 1.1 & 1.7 \\
\hline $\mathbf{2 \times 8 0}$ & 1.7 & 2.8 \\
\hline $\mathbf{3 \times 8 0}$ & 2.1 & 3.6 \\
\hline $\mathbf{4 \times 8 0}$ & -1.4 & 1.1 \\
\hline $\mathbf{5 \times 8 0}$ & 2.8 & 2.6 \\
\hline
\end{tabular}

transmission for those channels. The extra losses are due to the accumulation of unoptimized high loss splices between the standard-type fiber used by BTL and the high-NA fiber used by Alcatel. Table II gives the penalty at $10^{-10}$ for the four wavelengths of the multiplex through the link. It can be 

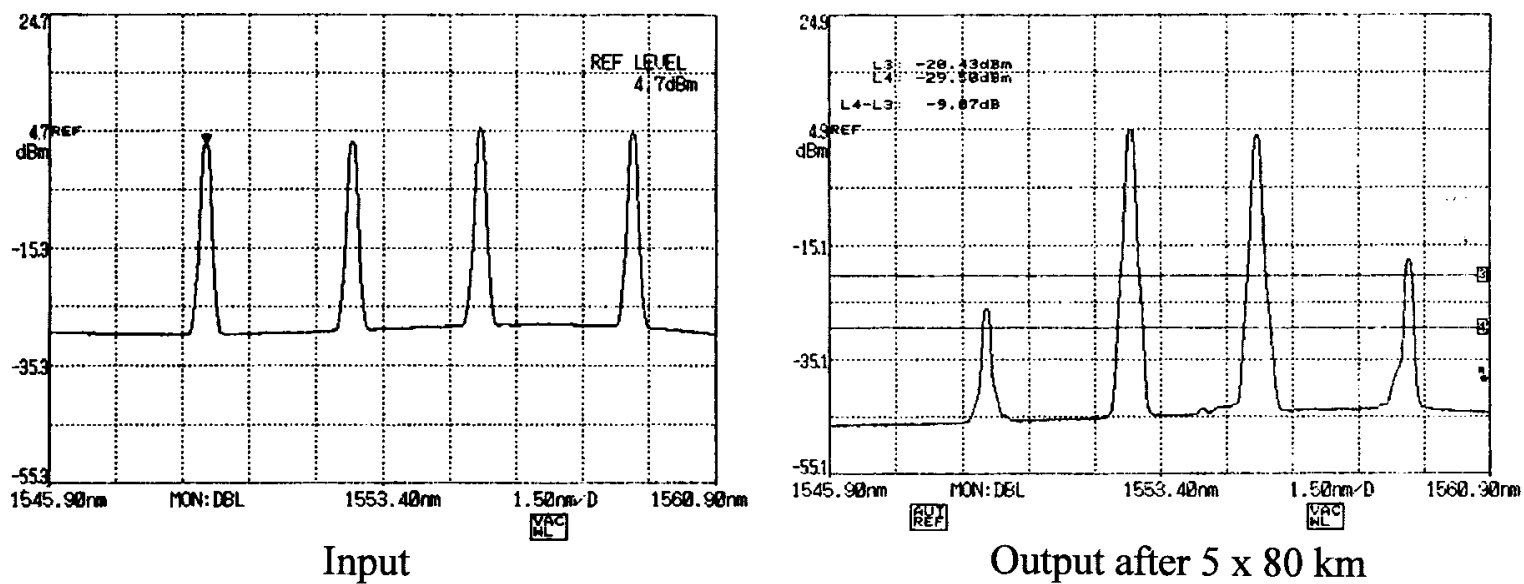

Output after $5 \times 80 \mathrm{~km}$

Fig. 15. Optical spectrum at the input and output of $4 \times 10 \mathrm{~Gb} / \mathrm{s}$ WDM transmission.

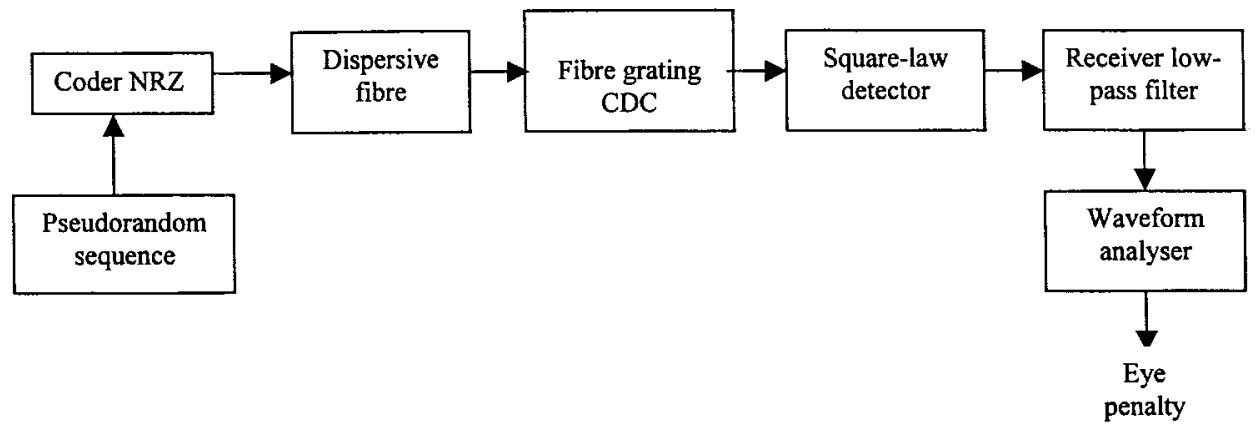

Fig. 16. System configuration used for numerical simulations.

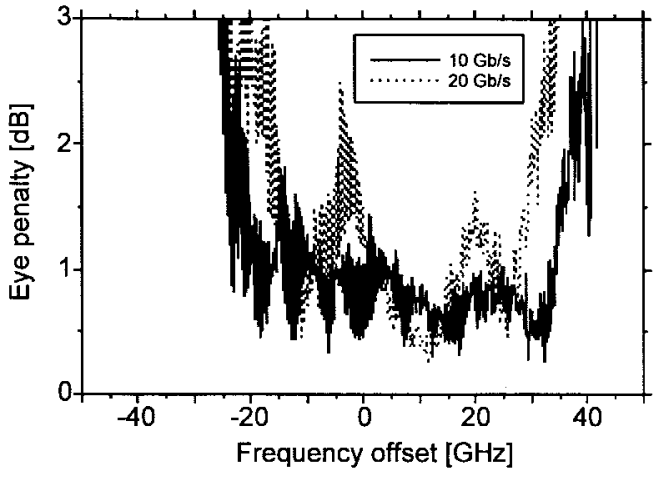

(a)

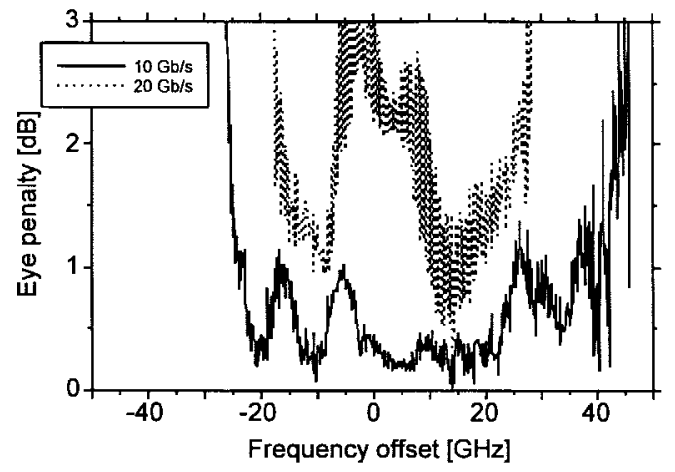

(c)

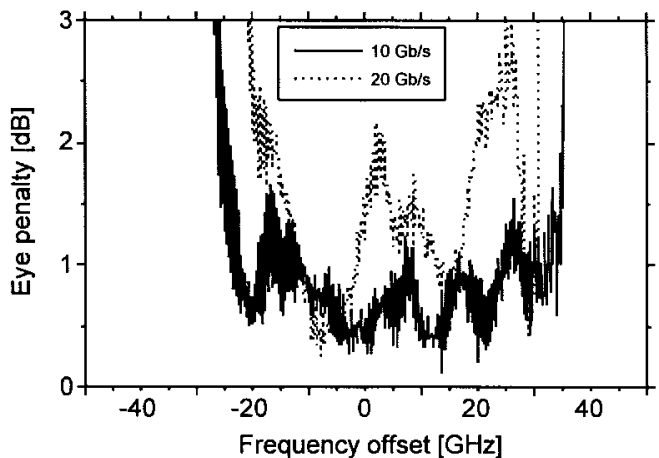

(b)

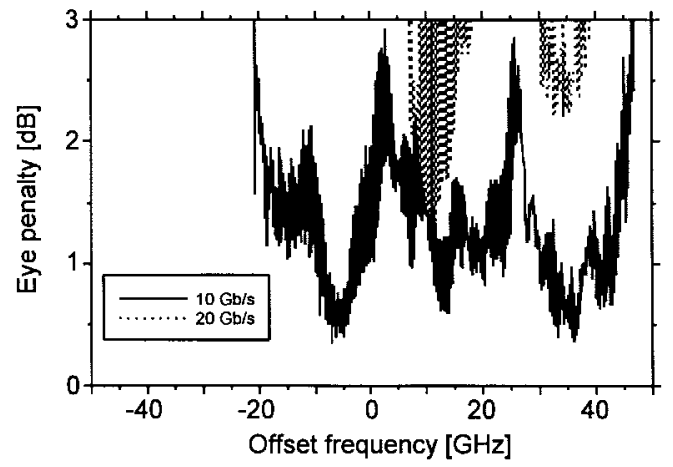

(d)

Fig. 17. (a)-(d) Computed eye closure penalty as a function of frequency offset for four gratings realized by British Telecom Laboratories at 10 and $20 \mathrm{~Gb} / \mathrm{s}$. 


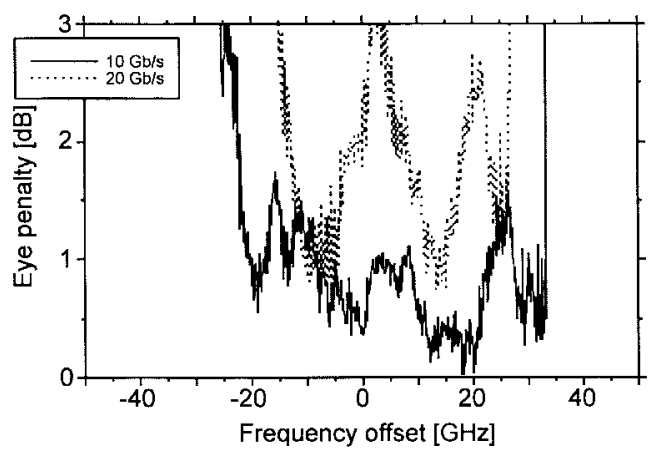

(a)

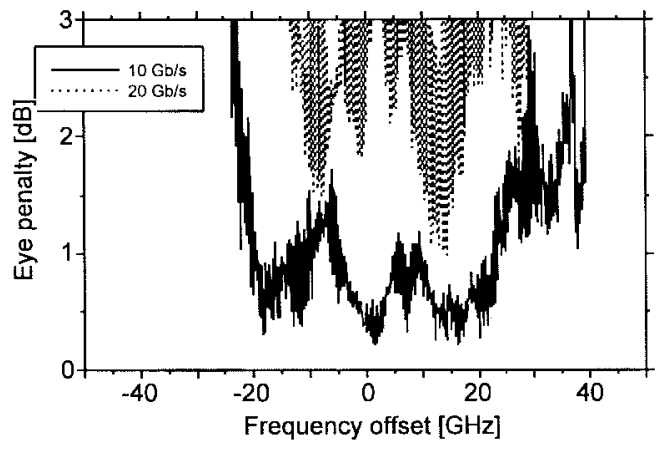

(c)

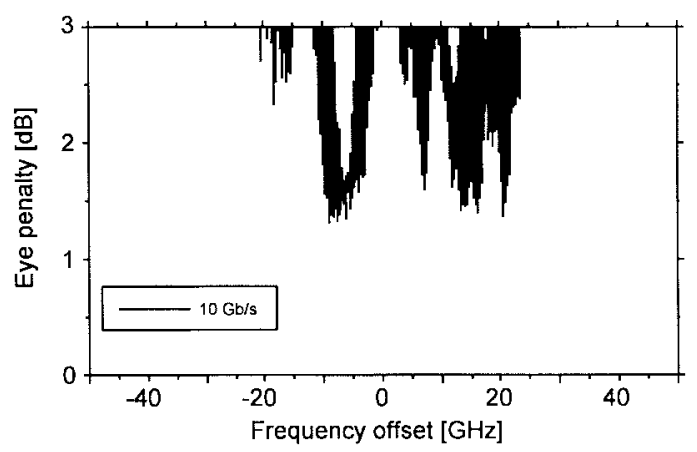

(b)

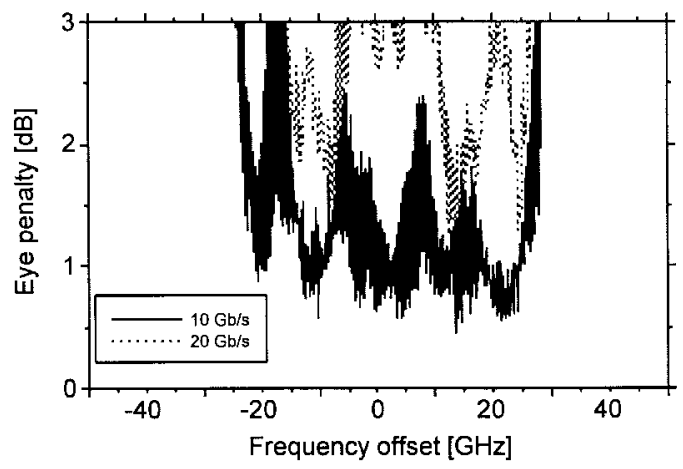

(d)

Fig. 18. Computed eye closure penalty as a function of frequency offset for the first two cascaded gratings realized by British Telecom Laboratories at (a) 10 and $20 \mathrm{~Gb} / \mathrm{s}$, and then, (b), (c), (d) the results for other possibilities of cascading two gratings.

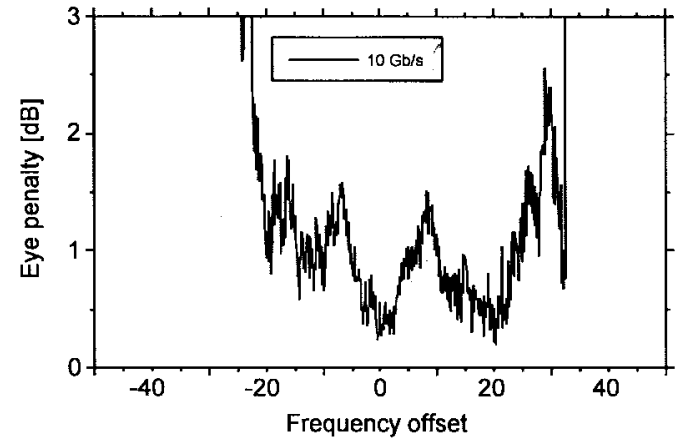

Fig. 19. Computed eye closure penalty as a function of frequency offset the first four cascaded gratings realized by British Telecom Laboratories at 10 $\mathrm{Gb} / \mathrm{s}$.

observed that the penalties for the central channels is erratic due to the variations of the time delays. These channels can be transmitted through $400 \mathrm{~km}$ of NDS fiber with less than $3 \mathrm{~dB}$ penalty at $10^{-10}$. The lateral channels at 1549 and $1559 \mathrm{~nm}$ could be propagated through only $80 \mathrm{~km}$ due to high optical losses with penalties at $10^{-10}$ of 1.9 and $2.2 \mathrm{~dB}$, respectively.

\section{MODELING}

System performances, in terms of eye closure penalty of the fabricated DCG's has been compared to the results of simulations. Measured spectra of reflectivity and time delay are used in the computation. This is done at $1555 \mathrm{~nm}$ (BTL's gratings) and at $1559 \mathrm{~nm}$ (Alcatels gratings) only.

For the simulations, propagation in the gratings is considered to be in the linear regime. Signal propagation within single-mode fibers is modeled by the nonlinear

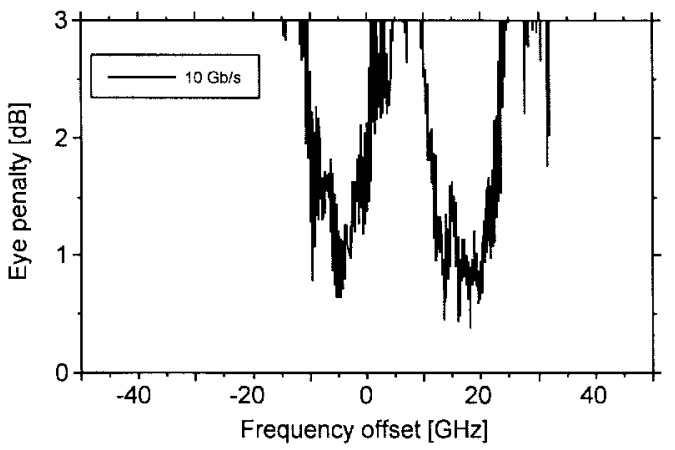

Fig. 20. Computed eye closure penalty as a function of frequency offset for the first three cascaded gratings realized by British Telecom Laboratories at $10 \mathrm{~Gb} / \mathrm{s}$.

Schrödinger equation (NSE) which includes the chromatic dispersion and the Kerr effect. The block diagram of an intensity modulation with direct detection (IM-DD) transmission system is illustrated in Fig. 16. The input waveform represents a nonreturn-to-zero (NRZ) coded PRBS of 128 bits at a transmission rate $B=10 \mathrm{~Gb} / \mathrm{s}$ or $B=20 \mathrm{~Gb} / \mathrm{s}$. The receiver filter is a fourth-order Bessel low-pass filter with the cutoff frequency equal to $0.75 \mathrm{~B}$. The dispersion of the fiber, used for computation, is $1800 \mathrm{ps} / \mathrm{nm}$ corresponding to $100 \mathrm{~km}$ of standard single-mode fiber. This is a little more than the length compensated for by the DCG's.

Fig. 17 shows the eye penalty at 10 and $20 \mathrm{~Gb} / \mathrm{s}$ as a function of frequency offset for four gratings from British Telecom Laboratories at $1555 \mathrm{~nm}$, corresponding to the spectra presented in Fig. 4. In Fig. 18 are shown the results for the first two cascaded gratings and for the other possibilities of 


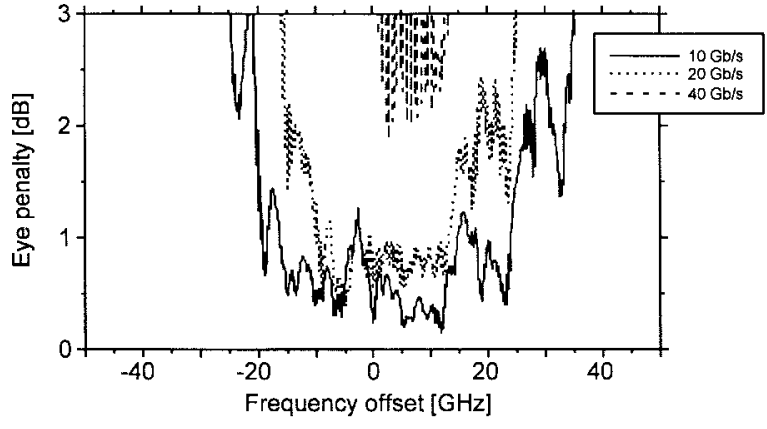

(a)

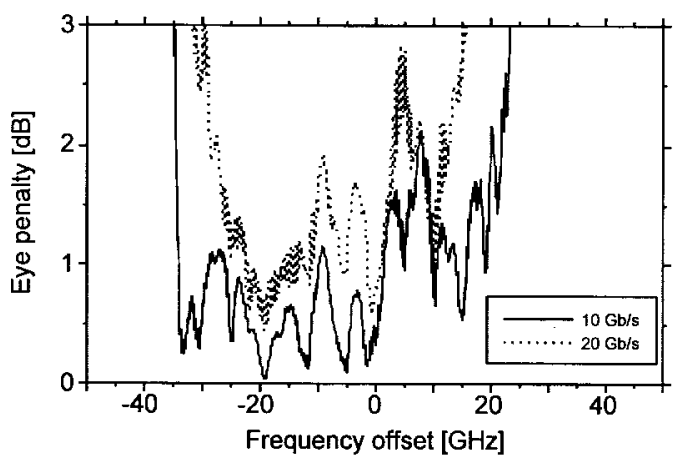

(c)

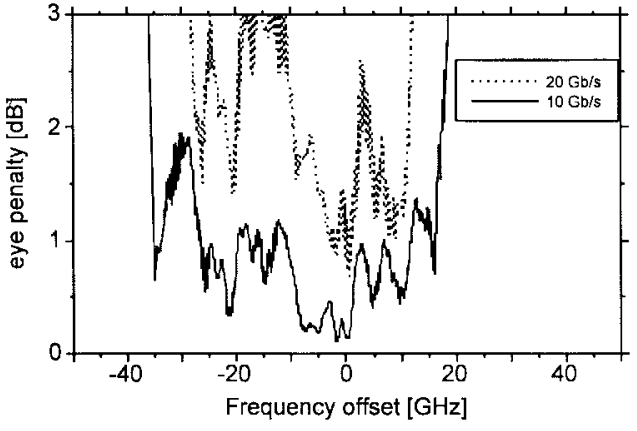

(b)

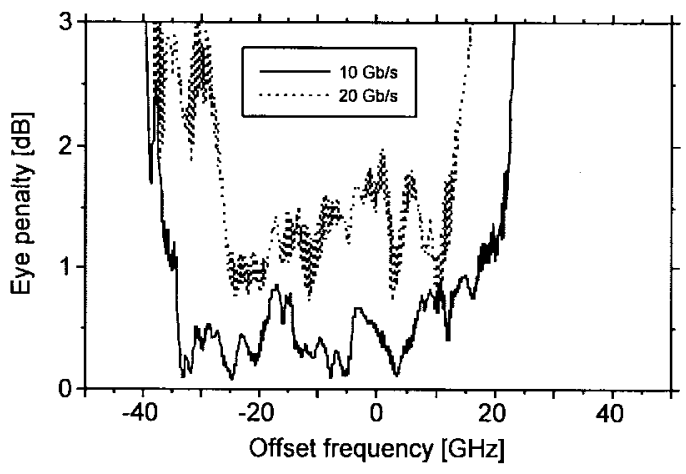

(d)

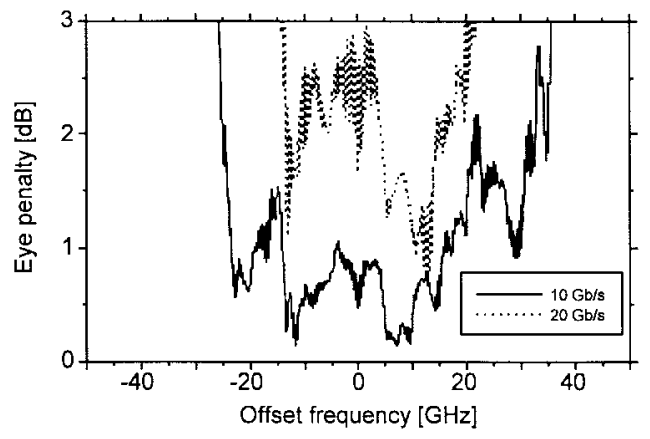

(e)

Fig. 21. Computed eye closure penalty as a function of frequency offset for the five gratings at $1559 \mathrm{~nm}$ realized by Alcatel ((a) 11142 , (b) 11145 , (c) 11147, , d) 11148 , and (e) 12003 ).

two cascaded gratings. Figs. 19 and 20 show the results of the simulation for the first three-cascaded and the first four-DCG's at $10 \mathrm{~Gb} / \mathrm{s}$ only.

Fig. 21 shows the eye penalty at 10 and $20 \mathrm{~Gb} / \mathrm{s}$ as a function of frequency offset for five gratings from Alcatel, corresponding to the spectra presented in Fig. 8. For the first grating, a computation has also been carried out at 40 $\mathrm{Gb} / \mathrm{s}$. Penalty values are nearly similar to those presented in Fig. 17 for gratings fabricated by symmetric stretch. The DCG's are cascaded in the following order: 11142,11145 , 11 147, 11148 , and 12003. Fig. 22 represents the calculated system performances for the first two CDC's, and then as each additional grating is added to the system. This generally shows a progressive narrowing of the utilisable bandwidth and points out the difficulty of making systems experiments. The wavelength has to be tuned to optimize transmission. Figs. 23 and 24 report respectively the results for the other possibilities of cascading two and three gratings. From these computations, it appears that the sequence of DCG's can be optimized, owing to their nonidentical characteristics. For example, it would have been preferable to cascade gratings, 11142, 11148 and 12003 , as the first three.

\section{DISCUSSION}

We have presented two techniques for fabricating DCG's and results on system performances of a set of cascaded gratings fabricated by the techniques. The DCG's were not optimized and fabrication techniques have to be improved. However, experiments have already given good results and several observations have been made. We could cascade CDC's to compensate several hundreds of kilometers of fiber transmission. Four channels over $80 \mathrm{~km}$ and two channels over 400 $\mathrm{km}$ at $10 \mathrm{~Gb} / \mathrm{s}$ could be compensated for. 


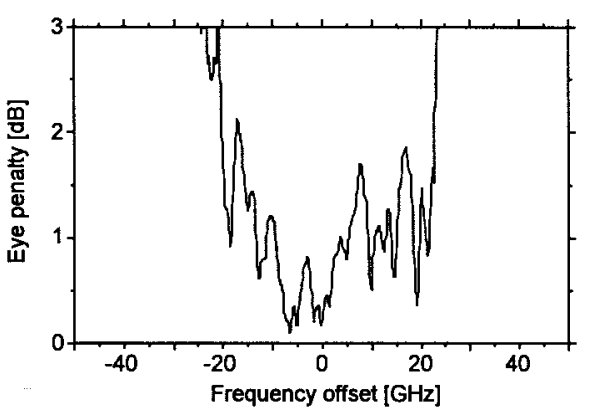

(a)

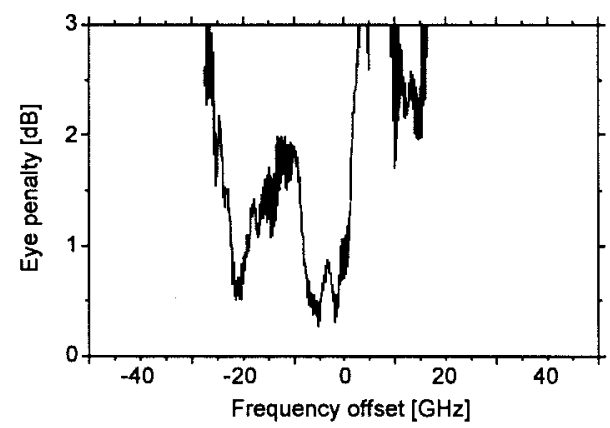

(c)

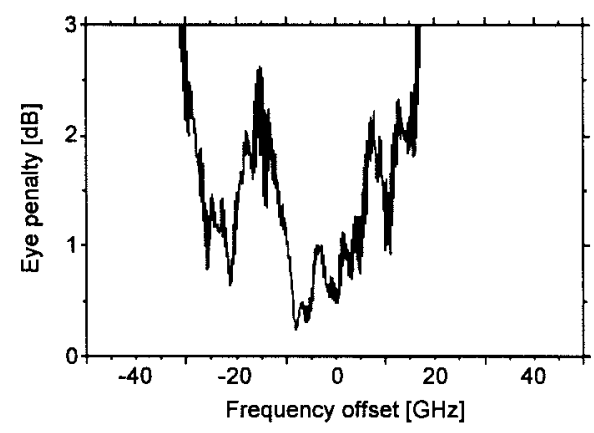

(e)

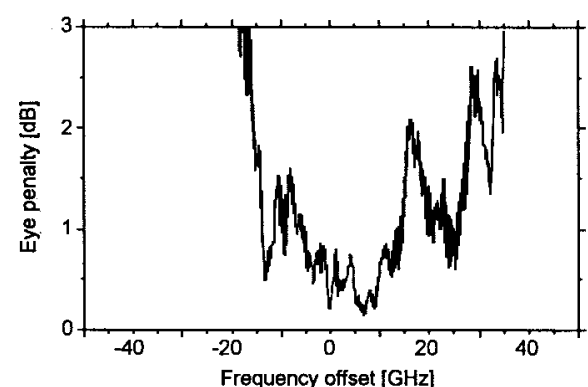

(b)

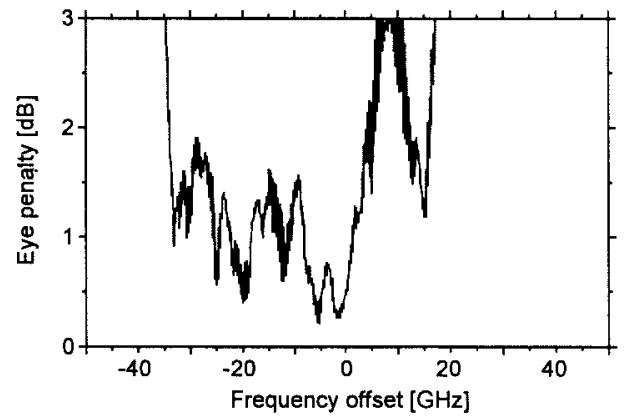

(d)

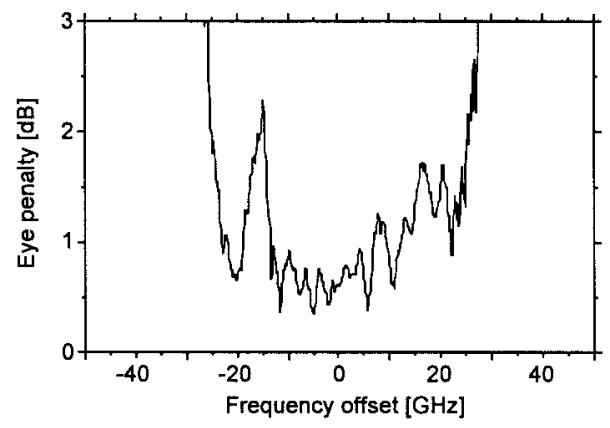

(f)

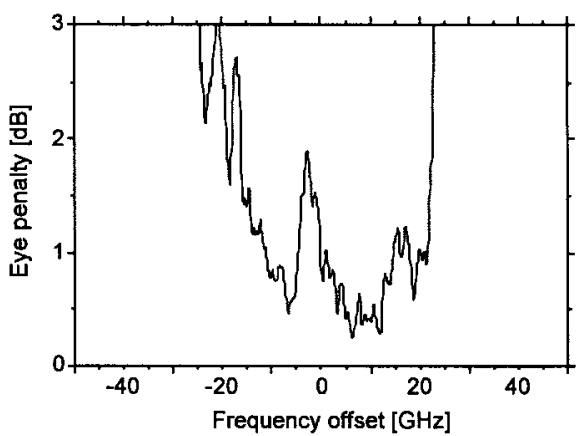

(g)

Fig. 22. Computed eye closure penalty as a function of frequency offset for the different possibilities of cascading two gratings. (a) $11142+11147$. (b) $11142+12003$. (c) $11145+11147$. (d) $11147+11148$. (e) $11452+11148$. (f) $11148+12003$. (g) $11142+11148$.

It was observed that fine tuning of the wavelength was necessary in order to optimize the transmission. This is attributed to group delay deviation that should be further decreased. Group delay deviation below $\pm 30 \mathrm{ps} / \mathrm{nm}$ is not sufficient for cascaded long haul systems.

Both experiments and simulations have shown that group delay deviations by cascading gratings in a different order could compensate each other. Penalty at $10^{-10}$ does not increase monotonously with the number of gratings. However, according to computations, they could also add to each other reducing the usable spectral bandwidth.

System experiments have revealed the extreme importance of optical losses due to splicing and low reflectivity. Our results show that splicing losses should be optimized to values 


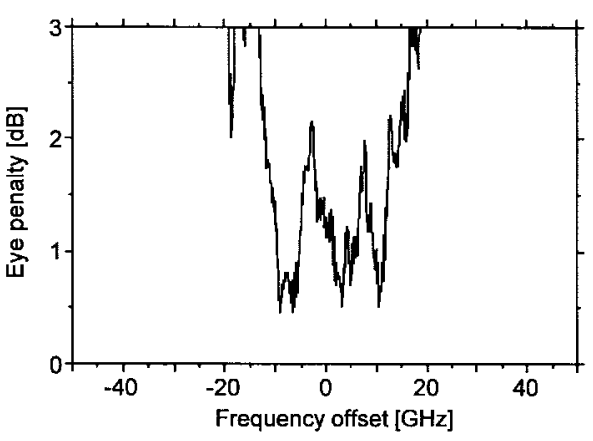

(a)

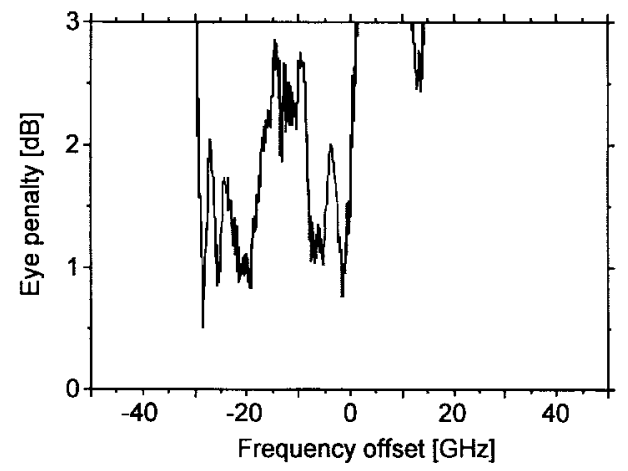

(c)

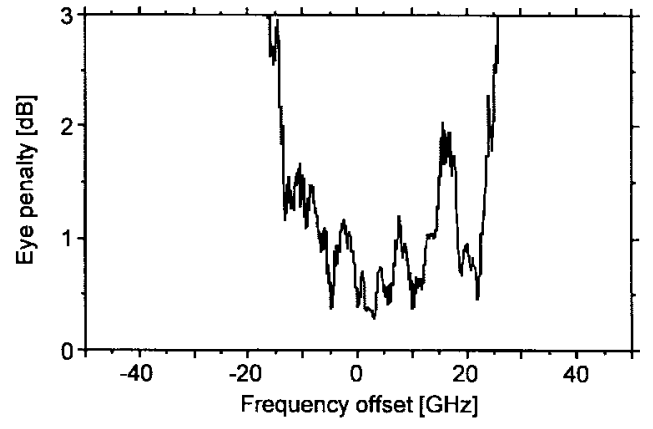

(b)

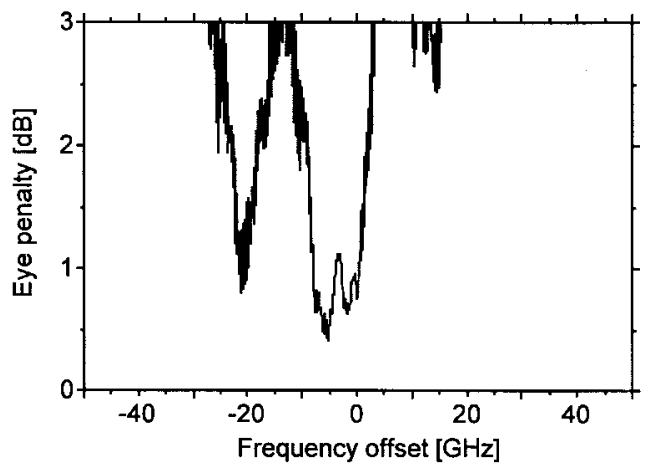

(d)

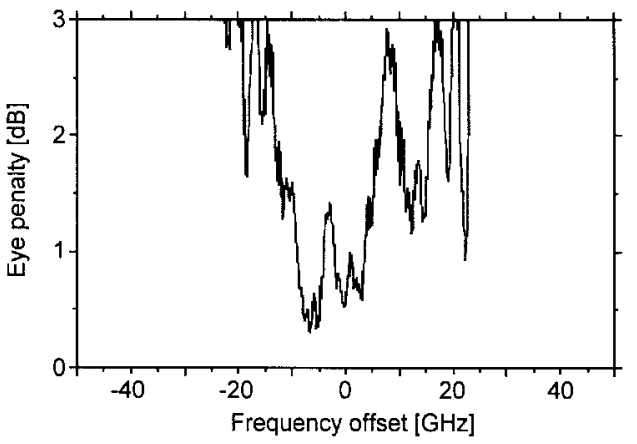

(e)

Fig. 23. Computed eye closure penalty as a function of frequency offset for the different possibilities of cascading three gratings. (a) $11142+11145+11148$. (b) $11142+11148+12003$. (c) $11145+11147+12003$. (d) $11145+11147+11148$. (e) $11142+11147+11148$.

better than $0.1 \mathrm{~dB}$ and that reflectivity of the DCG should be at least $90 \%$.

The influence of the input state of polarization on the operation of the DCG's and of the transmission line has also been highlighted. This has been further analyzed within the ACTS PHOTOS program and published in [16] by the CSELT and [17] by Alcatel.

Simulations and system experiments could not be fully compared (a chromatic dispersion of $1800 \mathrm{ps} / \mathrm{nm}$ was considered for simulations while a span of $80 \mathrm{~km}$ of standard telecom fiber was used in system experiments corresponding to a dispersion closer to $1400 \mathrm{ps} / \mathrm{nm}$ ) but are in good agreement. As expected, in general, measured penalties are a little higher than computed penalties.

Computations have also been carried out at transmission rates of 20 and $40 \mathrm{~Gb} / \mathrm{s}$. At $20 \mathrm{~Gb} / \mathrm{s}$, the computed eye closure penalties are slightly higher than at $10 \mathrm{~Gb} / \mathrm{s}$ in the case of smooth variations in the group delay spectrum and can even match that at $10 \mathrm{~Gb} / \mathrm{s}$. However, in the case of sharp variations, penalties are much higher (above $2 \mathrm{~dB}$, for instance) [18]. $40-\mathrm{Gb} / \mathrm{s}$ transmission was investigated for only one grating (11 142 at $1559 \mathrm{~nm}$ ) pointing out the necessity of fabricating extremely high quality gratings for compensation at high bit rates.

\section{CONCLUSION}

Two methods for the fabrication of dispersion compensating gratings has been studied within the ACTS program PHOTOS. Initial results on system performances of a first set of cascaded gratings fabricated by these techniques have been presented. The use of cascaded DCG's to compensate several hundreds of kilometers has been demonstrated. Compensation for four channels over $80 \mathrm{~km}$, and over 400 
$\mathrm{km}$ for two channels has been shown. These DCG's were not optimized for this application: the telescopic scanning technique has allowed the fabrication of good chromatic dispersion compensators for monochannel operation, however, for use in WDM transmission, the method has to be improved, especially the concatenation of the elementary gratings and the central wavelength positioning. Another fiber, with lower birefringence and adaptable to standard fiber must also be used. It has been demonstrated that the symmetric stretch scheme for fabricating apodized gratings can produce high quality gratings and that $< \pm 10$ ps deviation from linear dispersion is possible. Experiments have already given good results and pointed out several observations, especially the influence of the input wavelength on the time delays introduced by the DCG's as well as the necessity of reducing the optical losses. Good agreement has been observed between experiments and simulations of system performance.

\section{REFERENCES}

[1] F. Ouellette, "Dispersion cancellation using linearly chirped Bragg grating filters in optical waveguides," Opt. Lett., vol. 12, no. 10, pp. 847-849, 1987.

[2] R. Kashyap, A. Ellis, D. Malyon, H. G. Froehlich, A. Swanton, and D. J. Armes, "Eight wavelength $\times 10 \mathrm{~Gb} / \mathrm{s}$ simultaneous dispersion compensation over $100 \mathrm{~km}$ single-mode fiber using a single 10 nanometer bandwidth, 1.3 meter long, super-step-chirped fiber Bragg grating with a continuous delay of 13.5 nanoseconds," in Proc. ECOC'96, Oslo, Norway, vol. 5, pp. 5-10, postdeadline paper ThB.3.2.

[3] M. Durkin, M. Ibsen, M. J. Cole, and R. I. Laming, "1 m long continuously-written fiber Bragg gratings for combined second- and third-order dispersion compensation," Electron. Lett., vol. 33, no. 22, pp. 1891-1893, 1997.

[4] L. D. Garett, A. H. Gnauck, F. Forghieri, V. Gusmeroli, and D. Scarano, " $8 \times 20 \mathrm{~Gb} / \mathrm{s}-315 \mathrm{~km}, 8 \times 10 \mathrm{~Gb} / \mathrm{s}-480 \mathrm{~km}$ WDM transmission over conventional fiber using multiple broadband fiber gratings," in Proc. OFC'98, San Jose, CA, postdeadline paper PD18-1.

[5] R. Kashyap, P. F. Mckee, R. J. Campbell, and D. L. Williams, "Novel method of producing all fiber photoinduced chirped gratings," Electron. Lett., vol. 30, no. 12, pp. 996-997, June 1994.

[6] R. Kashyap, Swanton, and D. J. Armes, "A simple technique for apodising chirped and unchirped fiber Bragg gratings," Electron. Lett., vol. 32, no. 13, pp. 1227-1229, 1996.

[7] R. Kashyap, R. Wyatt, and P. F. McKee, "Wavelength flattened saturated erbium amplifier using multiple side-tap Bragg gratings," Electron. Lett., vol. 29 , no. 11 , pp. 1025-1026, May 1993.

[8] D. L. Williams, B. J. Ainslie, J. R. Armitage, R. Kashyap, and R J. Campbell, "Enhanced UV photosensitivity in boron co-doped germanosilicate fibers," Electron. Lett., vol. 29, no. 1, pp. 45-46, Jan. 1993.

[9] J. Martin, J. Lauzon, S. Thibault, and F. Ouellette, "Novel writing technique of long highly reflective in fiber gratings and investigation of the linearly chirped component," in Proc. Conf. Optical Fiber Communications (OFC'94), p. 138, postdeadline paper PD29-1.

[10] R. Kashyap, A. D. Ellis, D. J. Malyon, J. P. Hueting, H. G. Froelich, A. Swanton, and D. J. Armes, "Four wavelength dispersion compensation over $125 \mathrm{~km}$ of single mode optical fiber at $10 \mathrm{~Gb} / \mathrm{s}$ using multiple in-line step-chirped gratings," in Proc. ECOC'96, Oslo, Norway, pp. 87-90, paper MoB.4.3.

[11] R. Kashyap, in Fiber Bragg Gratings. New York: Academic, 1999, ch. 9 , p. 425

[12] I. Riant, J. Gourhant, F. Bruyère, S. Gurib, J. Da Loura, and P. Sansonetti, "New fabrication technique of fiber Bragg gratings with arbitrary chirp and wavelength for chromatic dispersion compensation," in ECOC'98, p. 415.

[13] J. D. Prohaska, E. Snitzer, S. Risthon, and V. Boegli, "Magnification of mask fabricated fiber Bragg gratings," Electron. Lett., vol. 29, no. 18, Sept. 1993.

[14] M. Lacerda-Rocha and R. Kashyap, "Characterisation of fibre Bragg gratings: A study on accuracy and repeatability,," in Dig. 4th Optical Fibers Measurements Conf. (OFMC'97), 1997, pp. 14-17.
[15] R. Kashyap, in Fiber Bragg Gratings. New York: Academic, 1999, ch. 7 , p. 336.

[16] M. Schiano and G. Zaffiro, "Polarization mode dispersion in chirped fiber gratings," in ECOC'98, p. 403.

[17] I. Riant, J. Gourhant, and P. Sansonetti, "Polarization mode dispersion analysis in fiber chromatic dispersion compensators," in Proc. OFC'99, pp. 269-271.

[18] D. Garthe, G. Milner, and Y. Cai, "System performance of broadband dispersion compensating gratings," Electron. Lett., vol. 34, no. 6, pp. 582-583, Mar. 1998.

Isabelle Riant was born in 1966. She graduated from the Ecole Suprieure d'Optique, Orsay, France, in 1990.

She then joined the Electrical Engineering Department at the University of Maryland to work on antireflection coatings for semiconductor amplifiers. In 1992, she joined Alcatel Corporate Research Center, where her first interests were distributed optical fibre amplifiers and FBG technology and devices. She rapidly devoted her work entirely to FBG's and she is now leader of the group studying in this field.

Salim Gurib was born in Mauritius in 1963 He received the Ph.D. degree in 1990 at the LOPM Duffieux, University of Besancon, France, for the definition of tunable optical sources.

In 1991, he joined the Alcatel Corporate Research Center, Optical Component Division, where his fields of interest were III-V semiconductor optical components for coherent transmission, for optical switching and routing and for access. In 1996, he joined the system department and worked on terrestrial WDM systems, Optical Phase Conjugation for submarine applications and is currently working on DWDM transmissions systems with very low channel spacings.

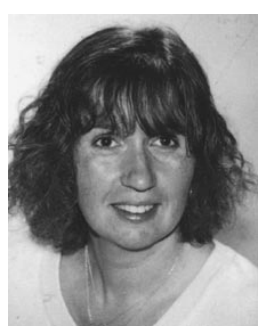

Josselyne Gourhant was born in 1957 in Paris, France. She graduated from Fresnel Optics school. After several years in accoustooptical technology, she is currently working on chromatic dispersion compensation using FBG's.

Pierre Sansonetti was born in Paris, France, in 1957. He graduated from Ecole Polytechnique in 1979 and Ecole Nationale Superieure des Telecommunications in 1981.

He then worked from 1981 to 1987 at Centre National des Telecommunications first on optical fibres modeling and characterization and then on monolithic integration of laserd diode and external modulator in III-V semiconductor. He then worked at Bertin until 1992 on optical fibre sensors, and since then is at Alcatel Corporate Research Centre working on optical fiber components. 


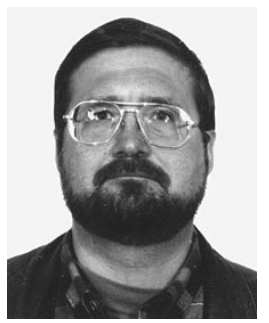

Christian Bungarzeanu received the Dipl. Eng. degree in electrical engineering from the Polytechnic University of Bucharest, Romania, in 1983 and the Ph.D. degree in telecommunication engineering from the Swiss Federal Institute of Technology-Lausanne, Lausanne, Switerzland, in 1995.

Since 1990, he is with the Telecommunications Laboratory of the Swiss Federal Institute of Technology-Lausanne. He was recently involved in the European ACTS project PHOTS (photosensitive Technology for Optical Systems). He is currently Senior Scientist and his research interests include numerical simulation of lightwave transmission systems, all optical networks, dimensioning and optimisation of fibre-optic communication networks. He teaches undergraduate courses on optical communications.

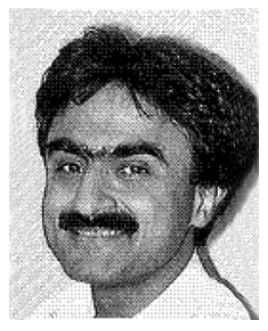

Raman Kashyap received the B.Sc degree from King's College London, U.K., and the Ph.D. degree in physics from Essex University, U.K.

He worked at BT Laboratories on optical fiberbased devices, measurements, and nonlinear optics. $\mathrm{He}$ has researched fiber Bragg gratings since the very early day of the field. He has published approximately 200 papers in journals, books, and conferences, has presented numerous invited talks at many conferences around the world, and authored the first book on fiber Bragg gratings. He invented the step-chirped phase-mask, novel apodization techniques for the fabrication of chirped Bragg gratings for dispersion compensation, and played a key technical role in the ACTS PHOTOS program. 